\title{
DEXTROSE GEL AND INFANT FORMULA ARE MORE EFFECTIVE THAN BREAST MILK
} FOR REVERSING NEONATAL HYPOGLYCAEMIA

\author{
D.L. Harris ${ }^{1,2}$, P.J. Weston ${ }^{1}$, J.E. Harding ${ }^{2}$ \\ ${ }^{l}$ Newborn Intensive Care Unit, Waikato Hospital, Hamilton, ${ }^{2}$ Liggins Institute, University of Auckland, \\ Auckland, New Zealand
}

Background: Neonatal hypoglycaemia is common and associated with brain injury. We have shown that oral dextrose gel successfully treats hypoglycaemia. The aim of this post-hoc analysis was to determine the contribution of dextrose gel, breast feeding, expressed breast milk and formula on the change in blood glucose concentration.

Methods: Eligible babies were $\geq 35$ weeks gestation, $<48 \mathrm{~h}$ old, and enrolled in a randomised trial (the Sugar Babies Study). Hypoglycaemic babies $(<2.6 \mathrm{mmol} / \mathrm{l})$ were encouraged to feed and randomised to dextrose or placebo gel. Hypoglycaemic episodes treated with a single dose of gel were included if blood glucose concentrations were measured again within 90 minutes. The effect of gel and feeds on change in blood glucose concentration was analysed using step-wise multiple regression. Data are mean (SD) or betacoefficient (95\% confidence intervals).

Results: Of the 514 babies in the Sugar Babies study, 213 had 266 hypoglycaemic episodes. Episodes were treated with dextrose gel (133) or placebo (133) plus combinations of breast-feeding (129), expressed breast milk (116), formula (39) or no milk (16). Blood glucose concentration increased by $0.7(0.6) \mathrm{mmol}^{-1}$ after treatment. Significant predictors of this change were dextrose gel $\left(\beta=0.23(0.10-0.36) \mathrm{mmol.} \mathrm{l}^{-1}, \mathrm{p}<0.001\right)$, volume of formula $\left(\beta=0.07(0.04-0.10) \mathrm{ml} . \mathrm{kg}^{-1} \cdot \mathrm{mmol}^{-1}, \mathrm{p}<0.001\right)$, and time since gel administration $\left(\beta=0.009(0.004-0.014) \mathrm{mmol}^{-1} \cdot \mathrm{min}^{-1}, \mathrm{p}<0.001\right)$.

Conclusion: Neonatal hypoglycaemia responds to dextrose gel and formula milk. Breast fed babies should receive dextrose gel as treatment for hypoglycaemia. 